\title{
Single Step Extractions of Metals in Coal Fly Ash
}

\author{
Lokeshappa B ${ }^{1,2}$, Anil Kumar Dikshit ${ }^{1,3,4, *}$ \\ ${ }^{1}$ Centre for Environmental Science and Engineering, Indian Institute of Technology Bombay, 400076, India \\ ${ }^{2}$ Department of Civil Engineering, University BDT College of Engineering, Davangere, 577004, India \\ ${ }^{3}$ School of Civil Engineering, Survey and Construction, University of KwaZulu-Natal, Durban, 4041, South Africa \\ ${ }^{4}$ School of Civil and Environmental Engineering, Nanyang Technological University, 639798, Singapore
}

\begin{abstract}
There is an increasing use of coal and subsequently large amounts of fly ash is generated in the thermal power plants in India and elsewhere in the world. Hence it becomes increasingly important to be able to assess the environmental risks involved in the management and disposal of fly ash materials. The fly ashes contain toxic metals that can be released into the environment through the coal combustion processes and through the leaching during disposal/ wet storage/ reuse of fly ash. The evaluation of the optimum time for leaching of the toxic metals and metalloids present in the three fly ashes was determined using the single step extraction procedure. The optimum time of 4 hours agitation was determined for the water soluble step as well as that for ion exchangeable step while the optimum time was 24 hours agitation in the acid soluble and reducible steps.
\end{abstract}

Keywords Coal Fly Ash, Extraction Procedure, Leaching, Metals

\section{Introduction}

India is the third largest producer of coal and coal based thermal power plant installations in India contribute about $70 \%$ of the total installed capacity for power generation[1]. However, the bituminous and sub-bituminous coals used contain over $40 \%$ ash content. At present, $120-150$ million tons of coal fly ash is generated from 120 existing coal based thermal power plants in India[2]. Coal fly ash is an industrial waste generated from coal combustion process in thermal power plants. It is a fly ash, a coal combustion residue having a complex heterogeneous mixture of amorphous and crystalline phases and is generally fine powdered ferroaluminosilicate material with $\mathrm{Al}, \mathrm{Ca}, \mathrm{Mg}, \mathrm{Fe}, \mathrm{Na}$ and $\mathrm{Si}$ as the predominant elements. The coal fly ash also contains significant amounts of toxic metals such as $\mathrm{As}, \mathrm{Ba}, \mathrm{Hg}$, $\mathrm{Cr}, \mathrm{Ni}, \mathrm{V}, \mathrm{Pb}, \mathrm{Zn}$ and $\mathrm{Se}$ characteristically enriched in coal fly ash particles[3-5]. The coal fly ashes occupy more space in the premises of industrial plants and are mixed with water to discharge into fly ash settling ponds or land fills. Large quantities of coal fly ashes are stored in the form of waste heaps or deposits, whose contamination poses a serious threat to the environment as a major source of inorganic pollution. The behaviour of many metal pollutants and the release of such metals during storage can have deleterious effects on the environment as well as on human health[6]. Metals present in the ashes are originated from the compo-

* Corresponding author:

dikshit@iitb.ac.in (Anil Kumar Dikshit)

Published online at http://journal.sapub.org/re

Copyright (C) 2012 Scientific \& Academic Publishing. All Rights Reserved sition of the coal used in combustion, combustion conditions, removal efficiency of air pollution control device and method of coal fly ash disposal[7]. Major environmental implications of ashes are their disposal to landfill or reuse as the constructional materials. The toxic meals transformation in the coal fly ash to environment during coal combustion consists of several steps and is shown in the Figure 1.

Chemical process processes may then sequester or release metals during long term wet storage. The mobility of toxic metals from coal fired thermal power plant fly ashes show a wide compositional range is examined by sequential extraction producer in order to assess their mobility when these wastes are ponded or landfilled[8]. Extraction methods involve the complete or selective mobilization of toxic metals associated with the solid phase by extraction with aqueous solution. The retention of metals with fly ash and associated sorbents prevents their emission to the atmosphere, and the solid phases that are now enriched in the metals must be managed to prevent metal releases to groundwater and surface water. The leaching potential of metals depends on the composition of the aqueous leaching solution and on the speciation of the metal in the solid phase $[9,10]$.

In this present research work single-step extraction has been carried to integrate into the full sequential extraction procedure and to determine the optimum leaching time of the extractant to assessing the potential mobilization of metals ambient environmental conditions.

\section{Materials and Methods}

\subsection{Materials}




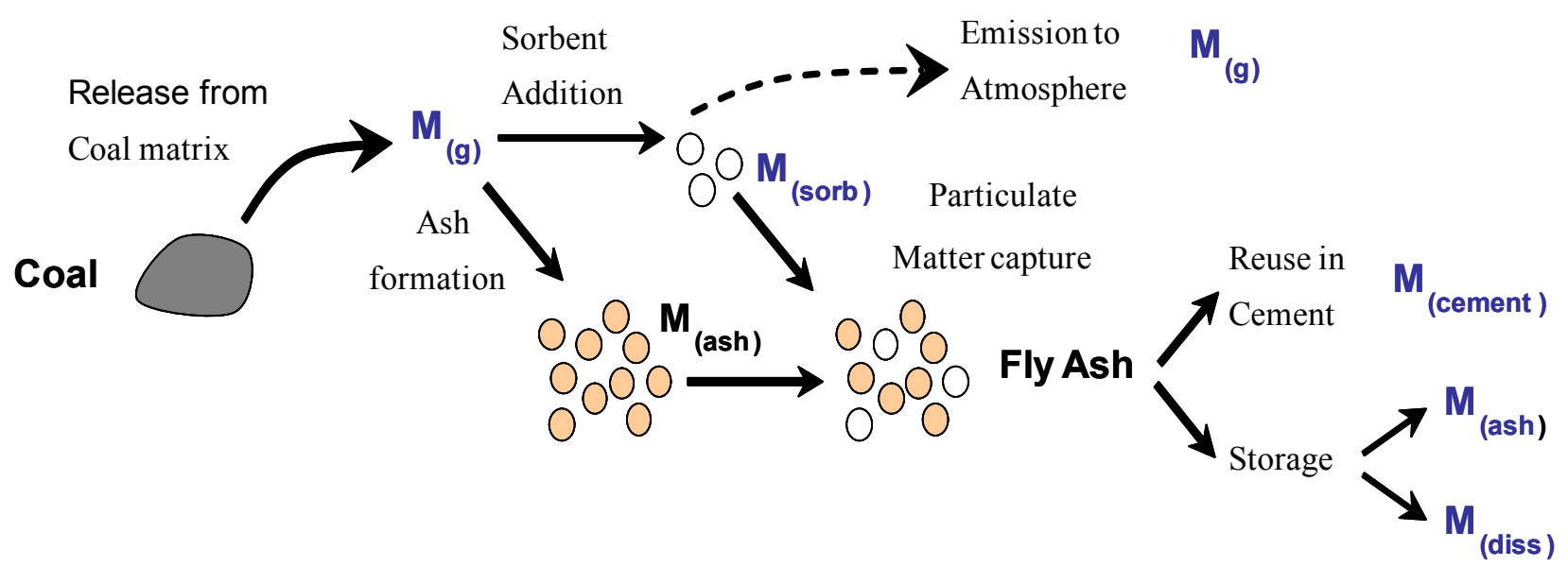

Figure 1. Toxic metals transformation in the coal fly ash to the environment

Three coal fly ash materials named as CFA1, CFA2 and CFA3 were collected from dust hoppers of electrostatic precipitators of three full-scale Indian power plants in and around Maharashtra. The power plants are using bituminous and sub-bituminous coals from India and from imported Indonesia. The coal fly ash materials were characterized for their ash contents, calcium oxide contents and mineralogy using X-ray diffraction.

Ultra pure water produced by TWF EDI UV TM, Water Kit (Semens, Singapore) was used for washing of glassware and preparation of reagents. Ammonium nitrate, acetic acid, sodium dithionite, sodium citrate, sodium bicarbonate, concentrated nitric and hydrochloric acids were used to prepare extractants for the single step extraction. The acetic acid, nitric and hydrochloric acids were trace metal grades. All chemicals were purchased from Merck chemical (Mumbai, India). The 25 element aqueous custom standard in $5 \% \mathrm{HNO}_{3}$ (ZOASIS 1004) from VHG Labs, Manchester, USA was used for calibration of ICP-AES. An aliquot of the standard was also used as control for the extraction tests.

\subsection{Single Step Extraction Procedure}

Single step extraction procedure (SSEP) was developed to optimize the leaching time to achieve optimum leaching of elements. The following extractions were carried out: (1) Ultrapure water was used to extract metals that were water soluble; (2) $1.0 \mathrm{M} \mathrm{NH}_{4} \mathrm{NO}_{3}$ was used to remove ion exchangeable metals; (3) $0.11 \mathrm{M}$ acetic acid targeted acid soluble metals; (4) a solution of $0.128 \mathrm{M}$ sodium dithionite, $0.3 \mathrm{M}$ sodium citrate, and $0.1 \mathrm{M} \mathrm{NaHCO}_{3}$ (DCB) was used to remove reducible metals. In all experiments, a solid to liquid ratio of $5.0 \mathrm{~g}$ ash $/ 500 \mathrm{~mL}(10 \mathrm{~g} / \mathrm{L})$ extractant was used and contents were stirred in a magnetic stirrer at 500 rpm. $10 \mathrm{~mL}$ samples were drawn after leaching time intervals of $1 \mathrm{hr}, 2 \mathrm{hr}, 4 \mathrm{hr}, 8 \mathrm{hr}, 12 \mathrm{hr}, 24 \mathrm{hr}, 30 \mathrm{hr}, 36 \mathrm{hr}$, and $48 \mathrm{hr}$, respectively. Each sample was centrifuged for 10 minutes at $10000 \mathrm{rpm}$ and the extractant was filtered with the $0.2 \mu \mathrm{m}$ PTFE filter and analyzed for major and minor metals using ICP-AES as given in section 2.3. The various steps are shown in the Table 1.

\subsection{Determination of Metals Concentrations}

Concentrations of trace metals in samples from SSEP were obtained using Jobin Yvon Horib ICP-AES (ULTIMA 2000, France). Prior to analysis, the samples were diluted with $2 \% \mathrm{HNO}_{3}$ solution. Dilution factor was kept as 1:10 for the water soluble step, 1:20 for the acid-soluble step and 1:50 for the other two steps. Calibration standards were analyzed in the same matrices as the samples.

Table 1. Steps of SSEP

\begin{tabular}{|c|c|c|}
\hline Steps & Phase for Leaching & Leaching Solution \\
\hline 1 & Water Soluble (WS) & Ultrapure Water \\
\hline 2 & Ion Exchangeable (IE) & 1.0 M Ammonium Nitrate \\
\hline 3 & Acid Soluble (AS) & 0.11 M Acetic Acid \\
\hline 4 & Reducible (RD) & $\begin{array}{c}0.158 \text { M Dithionite, 0.3 M } \\
\text { Citrate and 1.0 M Bicarbonate }\end{array}$ \\
\hline
\end{tabular}

\section{Results and Discussion}

\subsection{Properties of Coal Fly Ashes}

The properties of coal fly ashes are shown in the Table 3. Coal fly ashes are classified based on their calcium oxide contents. Coal fly ash CFA2 is class $\mathrm{C}$ ash being calcium-rich with greater than $10 \%$ calcium oxide while CFA1 and CFA3 are silica-rich class F having less than 10\% calcium oxide.

Table 3. Properties of Coal Fly Ash

\begin{tabular}{|c|c|c|c|}
\hline Properties & CFA1 & CFA2 & CFA3 \\
\hline $\begin{array}{c}\text { Average ash content } \\
\text { in coal (\%) }\end{array}$ & 25.0 & 1.9 & 38.6 \\
\hline Loss on ignition (\%) & 1.4 & 1.11 & 1.6 \\
\hline Coal fly ash classes* & $\mathrm{F}$ & $\mathrm{C}$ & $\mathrm{F}$ \\
\hline Minerals in fly ash & $\begin{array}{c}\text { Quartz and } \\
\text { mullite }\end{array}$ & $\begin{array}{c}\text { Quartz and } \\
\text { magnesium and } \\
\text { iron oxides }\end{array}$ & $\begin{array}{c}\text { Quartz and } \\
\text { mullite }\end{array}$ \\
\hline
\end{tabular}

*C-calcium rich and F-Silica rich ash 


\subsection{Optimization of Leaching Time}

The optimum leaching time required for attaining maximum leaching in different leaching media, viz., ultrapure water, ammonium nitrate, acetic acid, DCB and aggressive solution of 4:1 $\mathrm{HNO} 3$ and $\mathrm{HCl}$ were found out using single step extraction for each leaching media. The results obtained are discussed below.

\subsubsection{Water Soluble Fractions}

Trends observed for CFA1: Among major metals, all metals exhibited peak leaching concentrations at 4 hours except $\mathrm{Na}$, which leached about $80 \%$ of its maximum leaching concentration at 4 hours as shown in Figure 2(a). For minor metals more than $80 \%$ of maximum leaching was attained at 4 hours for all the metals except $\mathrm{Ni}$. Ni leached about $60 \%$ of its maximum concentration at 4 hours as shown in Figure 2(b).

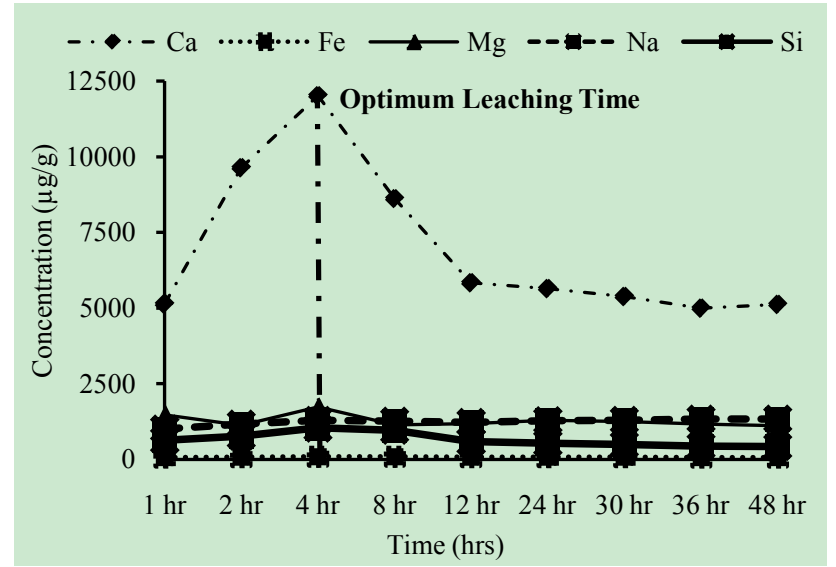

(a)

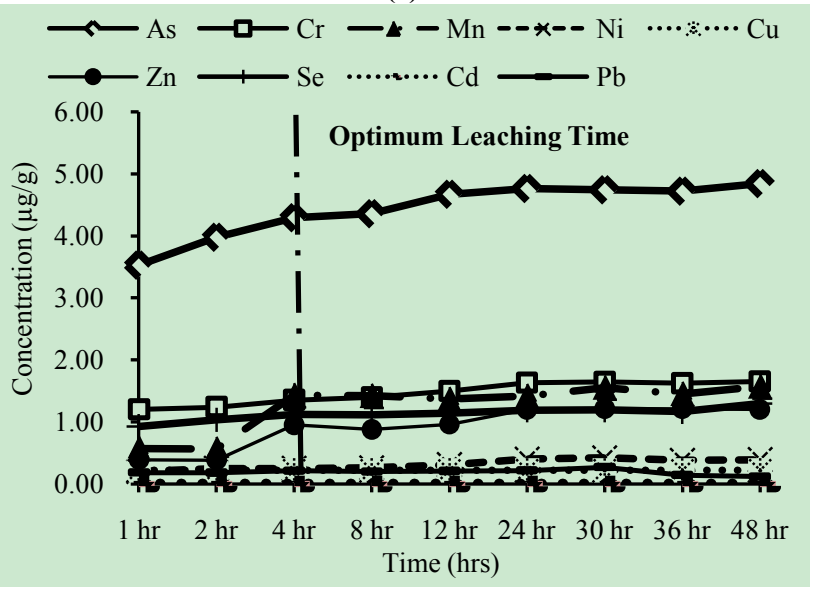

(b)

Figure 2. Leaching of water soluble fractions for CFA1, (a) Major metals, (b) Minor metals

Trends observed for CFA2: Among major metals, all metals exhibited more than $90 \%$ of their peak leaching concentrations at 4 hours except $\mathrm{Si}$, which leached about $70 \%$ of its maximum leaching concentration at 4 hours as shown in Figure 3(a). For minor metals maximum leaching was attained at 4 hours for all the metals except Mn, which leached about $65 \%$ of its maximum concentration at 4 hours as shown in Figure 3(b).

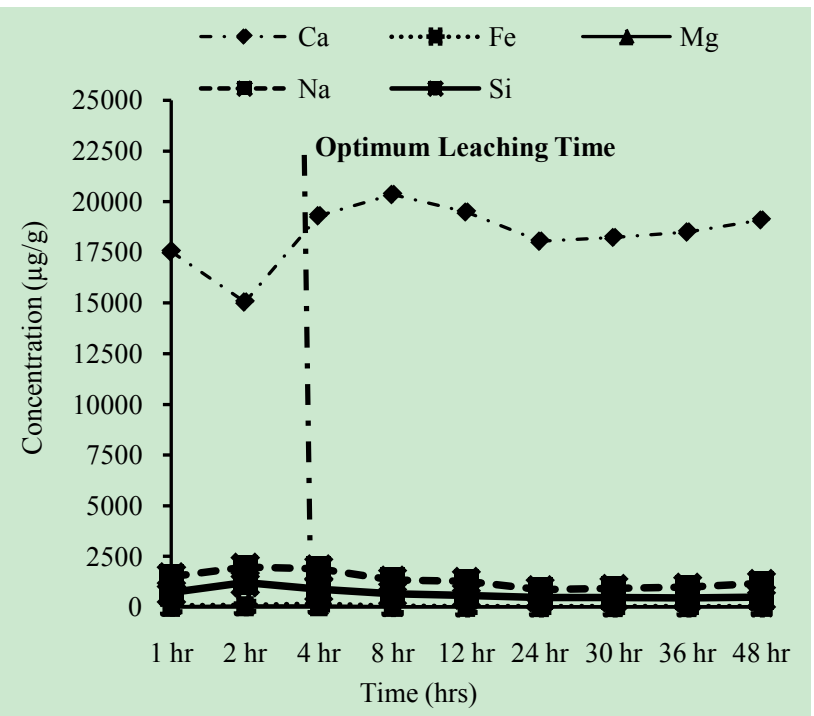

(a)

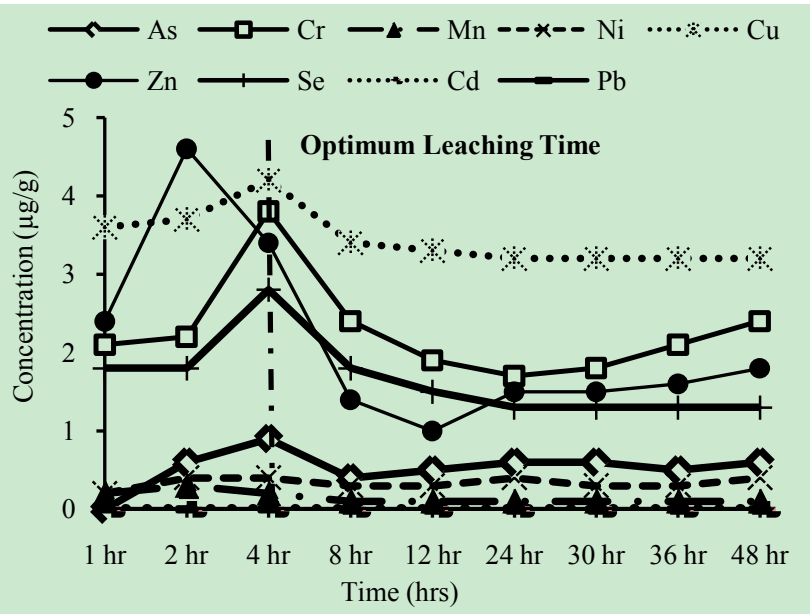

(b)

Figure 3. Leaching of water soluble fractions for CFA2, (a) Major metals, (b) Minor metals

Trends observed for CFA3: Among major metals, all metals exhibited their peak leaching concentrations at 4 hours except $\mathrm{Si}$, which leached about $90 \%$ of its maximum leaching concentration at 4 hours as shown in Figure 4(a). For minor metals maximum leaching was attained at 4 hours for all the metals except $\mathrm{Cr}$, which leached about $80 \%$ of its maximum concentration at 4 hours as shown in Figure 4(b).

\subsubsection{Ion Exchangeable Fractions}

Trends observed for CFA1: Among major metals, all metals exhibited peak leaching concentrations at 4 hours except $\mathrm{Ca}$ and $\mathrm{Mg}$ which leached about $95 \%$ of their maximum leaching concentration at 4 hours as shown in Figure 5(a). Among minor metals, $\mathrm{Cd}, \mathrm{Cr}, \mathrm{Ni}$ and $\mathrm{Zn}$ did not leach in ion exchangeable conditions, while Mn leached about $65 \%$ of its maximum leaching at 4 hours. The remaining metals showed their maximum concentration at 4 hours as shown in Figure 5(b). 

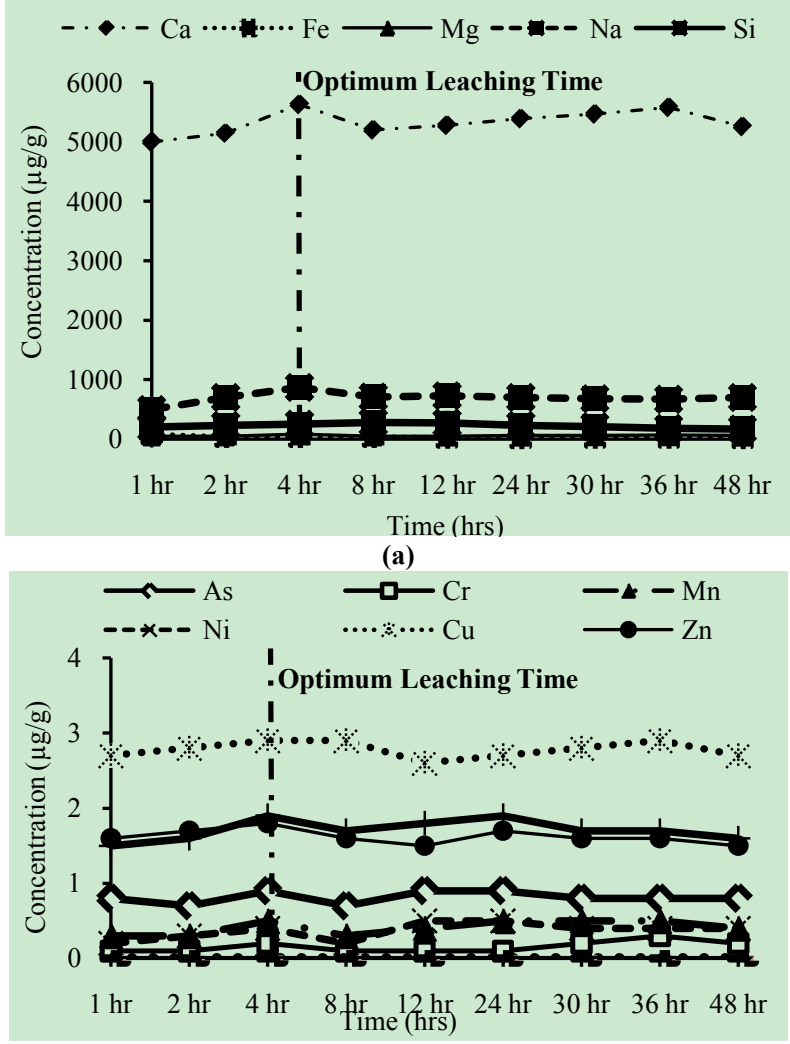

(b)

Figure 4. Leaching of water soluble fractions for CFA3, (a) Major metals, (b) Minor metals
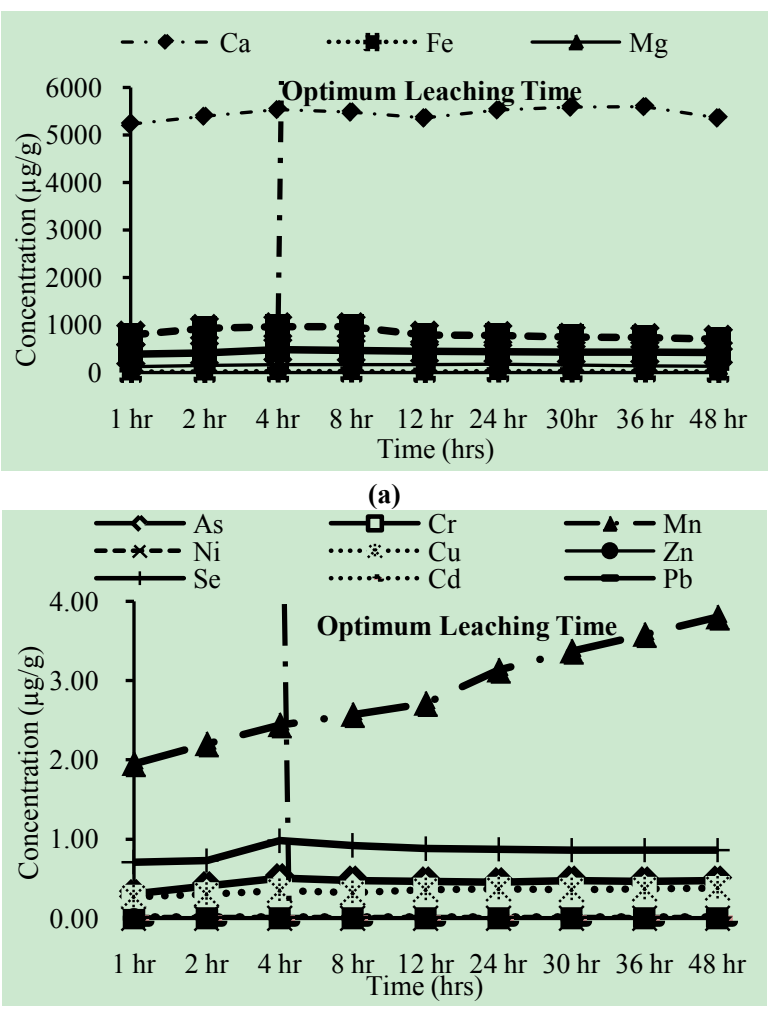

(b)

Figure 5. Leaching of ion exchangeable fractions for CFA1, (a) Major metals, (b) Minor metals

Trends observed for CFA2: Among major metals, $\mathrm{Ca}$ and
Fe exhibited peak leaching concentrations at 4 hours, $\mathrm{Na}$ and Si leached about $95 \%$ of their maximum leaching concentration at 4 hours, while $\mathrm{Mg}$ leached about $80 \%$ of its peak leaching concentration at 4 hours as shown in Figure 6(a). Among minor metals, Mn leached about $60 \%$ of its maximum leaching at 4 hours. The remaining metals showed their maximum concentration at 4 hours as shown in Figure 6(b).

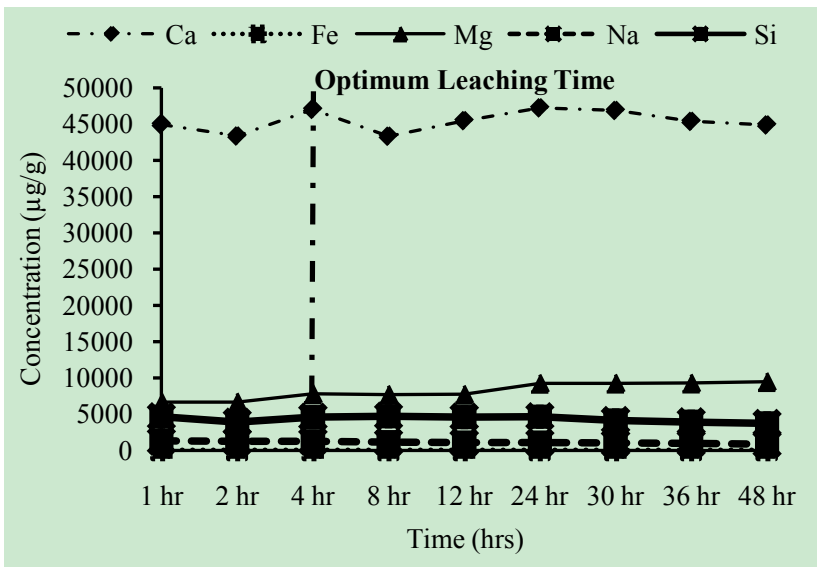

(a)

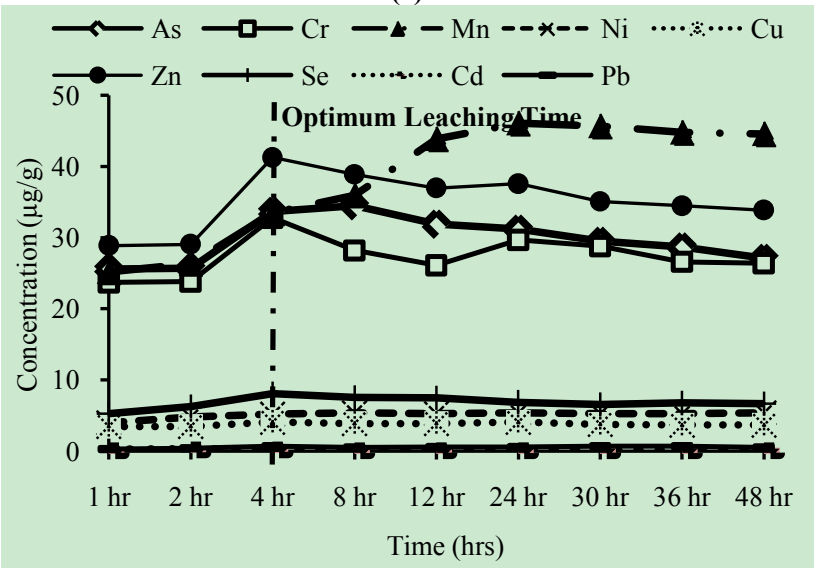

(b)

Figure 6. Leaching of ion exchangeable fractions for CFA2, (a) Major metals, (b) Minor metals

Trends observed for CFA3: Among major metals, $\mathrm{Ca}$ and $\mathrm{Mg}$ exhibited peak leaching concentrations at 4 hours, $\mathrm{Na}$ and $\mathrm{Si}$ leached about $90 \%$ and $95 \%$ of their maximum leaching concentration respectively at 4 hours, while $\mathrm{Fe}$ leached about $66 \%$ of its peak leaching concentration at 4 hours as shown in Figure 7(a). Among minor metals, $\mathrm{Cu}$ and $\mathrm{Zn}$ leached less than $70 \%$ of their maximum leaching concentration at 4 hours, while $\mathrm{Mn}$ and Ni leached about $85 \%$ of their peak concentration at 4 hours. The remaining metals showed their maximum concentration at 4 hours as shown in Figure 7(b).

\subsubsection{Acid Soluble Fractions}

Trends observed for CFA1: Among major metals, $\mathrm{Ca}$ and Fe exhibited peak leaching concentrations at 24 hours, while $\mathrm{Mg}$ and Si leached about $95 \%$ and $\mathrm{Na}$ leached about $85 \%$ of its peak leaching concentration at 24 hours as shown in Figure 8(a). Among minor metals, all metals exhibit more 
than $80 \%$ of their peak leaching concentrations at 24 hours, except $\mathrm{Mn}$ which leached about $70 \%$ of its maximum leaching at 24 hours as shown in Figure 8(b).
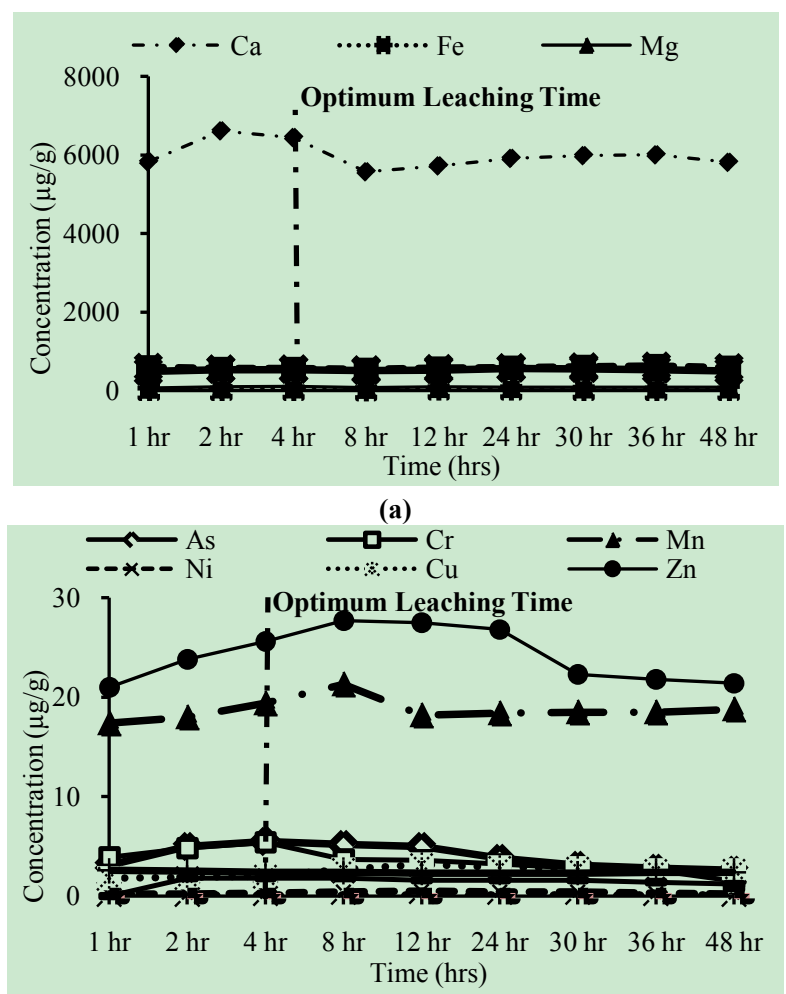

(b)

Figure 7. Leaching of ion exchangeable fractions for CFA3 (a) Major metals, (b) Minor metals
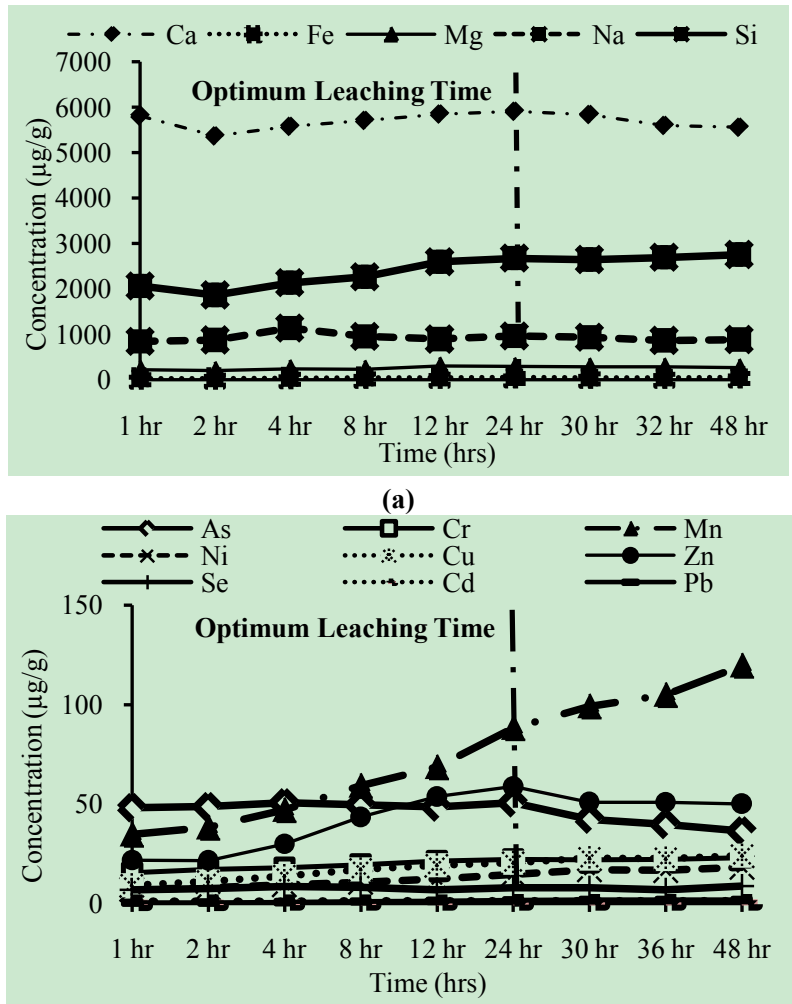

(b)

Figure 8. Leaching of acid soluble fractions for CFA1 (a) Major metals, (b) Minor metals
Trends observed for CFA2: Among major metals, Mg and Si exhibited peak leaching concentrations at 24 hours, while $\mathrm{Fe}$ and $\mathrm{Na}$ leached between $90 \%$ and $95 \%$ of their maximum leaching concentration at 24 hours and $\mathrm{Ca}$ leaches about $85 \%$ of its peak leaching concentration at 24 hours as shown in Figure 9(a). Among minor metals, all metals exhibit their peak leaching concentrations at 24 hours, except $\mathrm{Mn}$ and $\mathrm{Cr}$ which leached between $90 \%$ and $95 \%$ of their maximum leaching at 24 hours as shown in Figure 9(b).

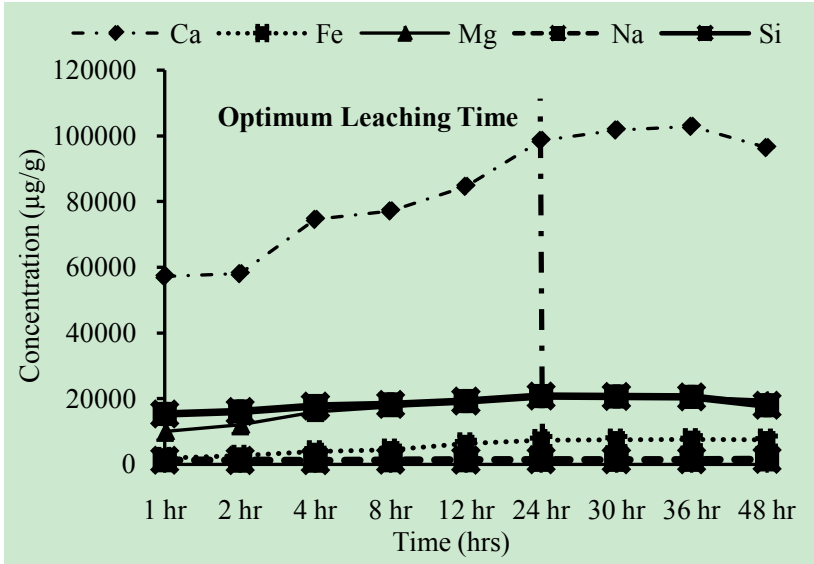

(a)

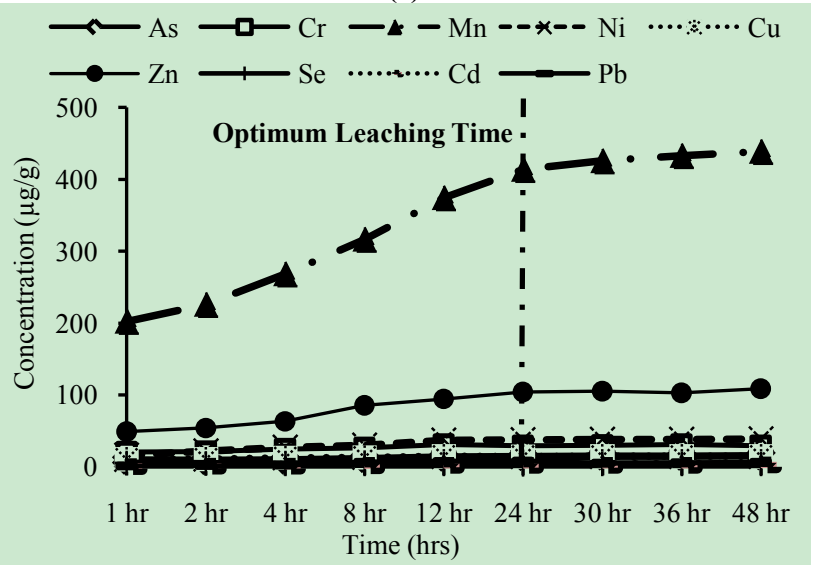

(b)

Figure 9. Leaching of acid soluble fractions for CFA2 (a) Major metals, (b) Minor metals

Trends observed for CFA3: Among major metals, $\mathrm{Ca}$ and $\mathrm{Na}$ exhibited peak leaching concentrations at 24 hours, while $\mathrm{Mg}, \mathrm{Na}$ and $\mathrm{Si}$ leached about $90 \%$ of their maximum leaching concentration at 24 hours as shown in Figure 10(a). Among minor metals, all metals exhibit their peak leaching concentrations at 24 hours, except $\mathrm{Mn}$ and $\mathrm{Cr}$ which leached about $90 \%$ of their maximum leaching at 24 hours as shown in Figure 10(b).

\subsubsection{Reducible Fractions}

Trends observed for CFA1: Among major metals, $\mathrm{Mg}, \mathrm{Si}$ and Fe exhibited peak leaching concentrations at 24 hours, while $\mathrm{Ca}$ and $\mathrm{Na}$ leached more than $95 \%$ of their maximum leaching concentration at 24 hours as shown in Figure 11(a). Among minor metals, all metals exhibit their peak leaching concentrations at 24 hours, except $\mathrm{Mn}$ and $\mathrm{Cr}$ which leached 
about $90 \%$ of their maximum leaching at 24 hours as shown in Figure11(b).
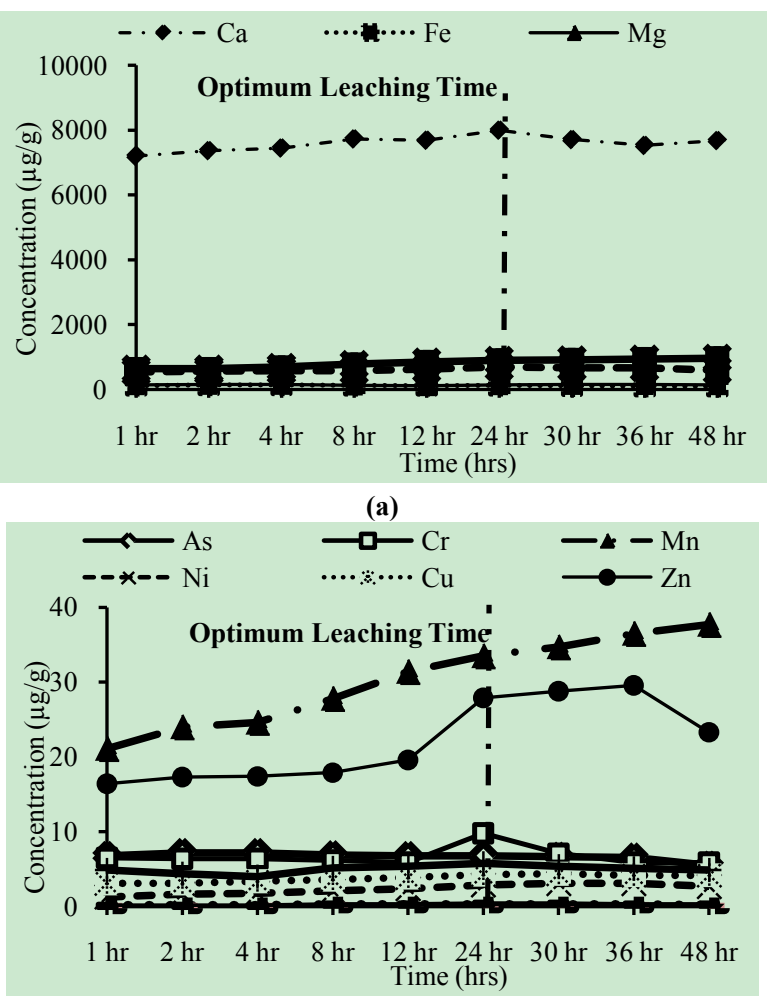

(b)

Figure 10. Leaching of acid soluble fractions for CFA3 (a) Major metals, (b) Minor metals
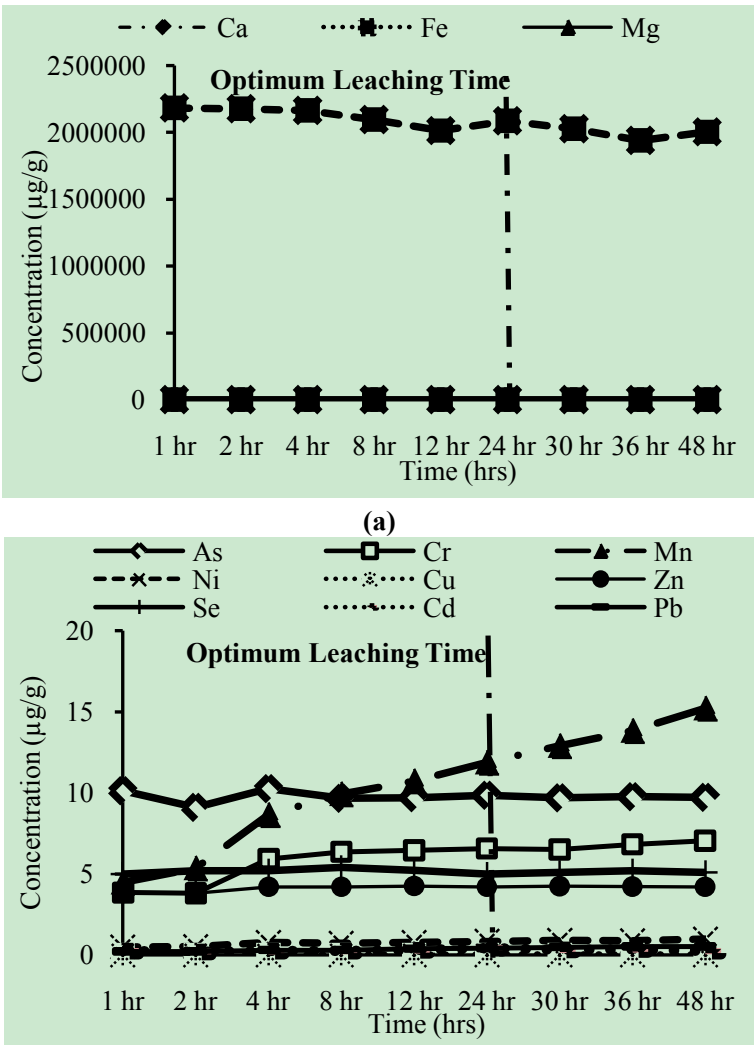

(b)

Figure 11. Leaching of reducible fractions for CFA1 (a) Major metals, (b) Minor metals
Trends observed for CFA2: Among major metals, $\mathrm{Mg}, \mathrm{Ca}$ and $\mathrm{Fe}$ exhibited peak leaching concentrations at 24 hours, while $\mathrm{Si}$ and $\mathrm{Na}$ leached more than $90 \%$ and $95 \%$ respectively of their maximum leaching concentration at 24 hours as shown in Figure 12(a). Among minor metals, all metals exhibit their peak leaching concentrations at 24 hours, except $\mathrm{Pb}$ and $\mathrm{Ni}$ which leached about $90 \%$ of their maximum leaching at 24 hours, while $\mathrm{Cr}$ showed a peak at 4 hours and decreased rapidly thereafter as shown in Figure12(b).

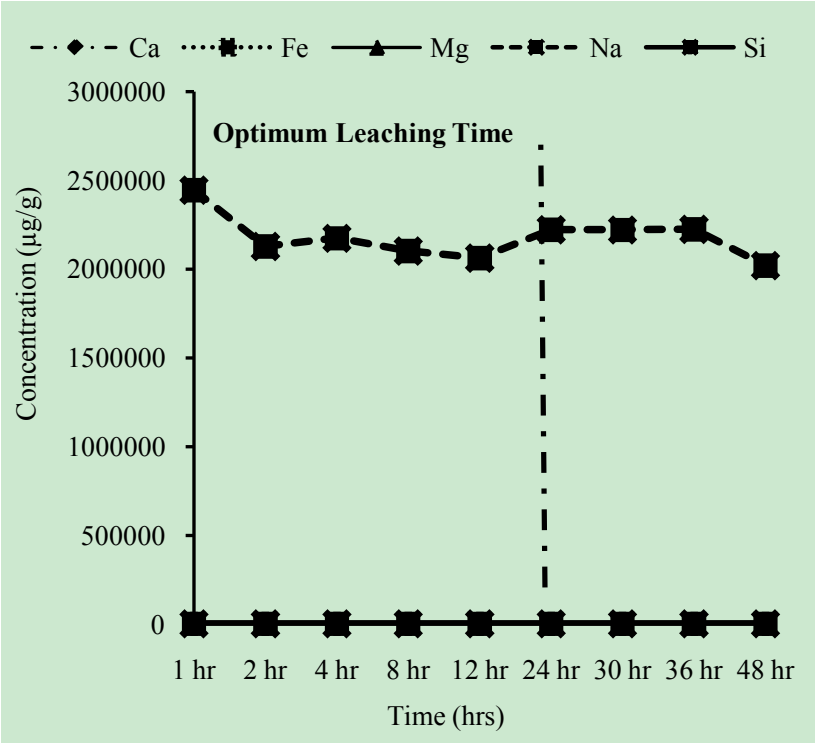

(a)

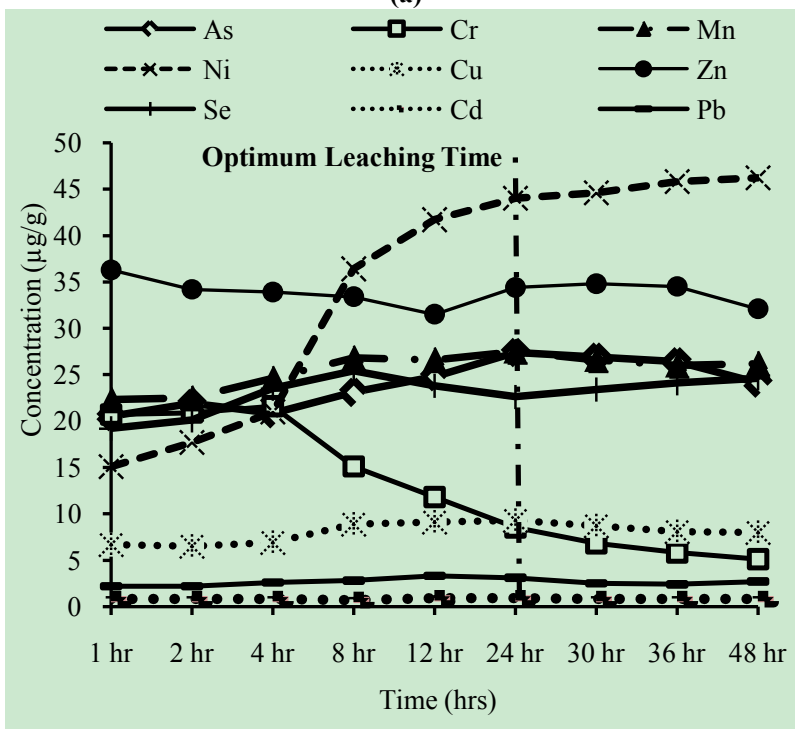

(b)

Figure 12. Leaching of reducible fractions for CFA2 (a) Major metals, (b) Minor metals

Trends observed for CFA3: Among major metals, Ca exhibited its peak leaching concentration at 24 hours, $\mathrm{Si}$ leached about $95 \%$ of its peak leaching concentration while $\mathrm{Na}, \mathrm{Mg}$ and $\mathrm{Fe}$ leached more than $90 \%$ of their maximum leaching concentration at 24 hours as shown in Figure 13(a). Among minor metals, all metals exhibit their peak leaching concentrations at 24 hours, except $\mathrm{Cr}, \mathrm{Cu}, \mathrm{Mg}$ and $\mathrm{Ni}$ which leached about $90 \%$ of their maximum leaching concentra- 
tions at 24 hours as shown in Figure13(b).

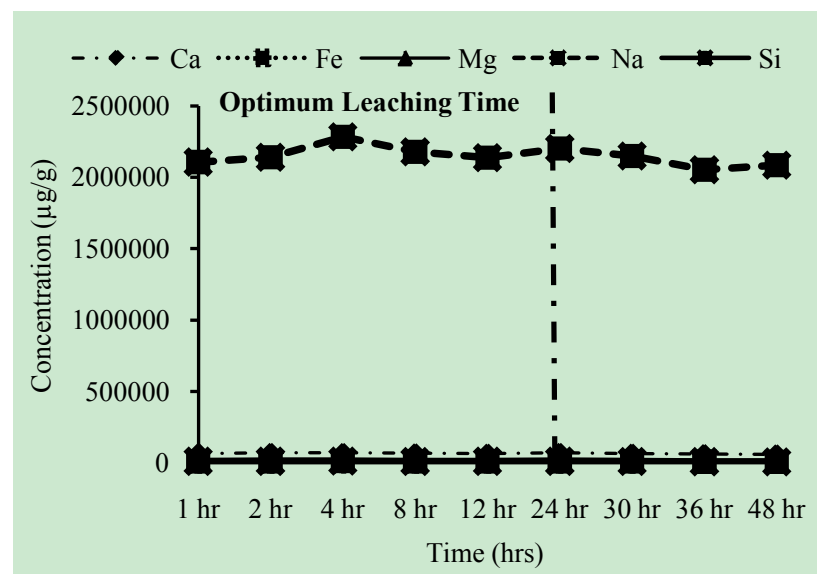

(a)

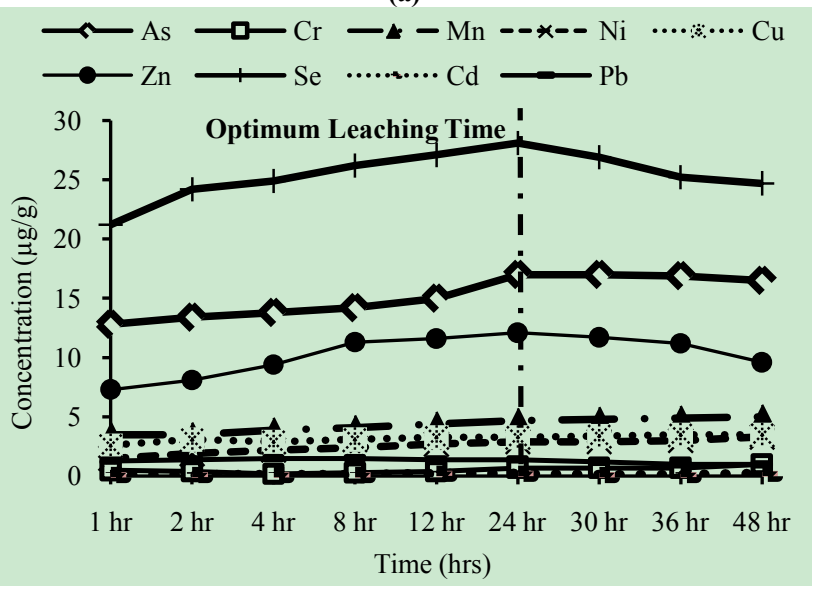

(b)

Figure 13. Leaching of reducible fractions for CFA3, (a) Major metals, (b) Minor metals

\section{Conclusions}

Water Soluble Fractions: Most of the metals exhibit more than $90 \%$ of their peak leaching concentrations at 4 hours, except $\mathrm{Si}, \mathrm{Na}, \mathrm{Ni}, \mathrm{Mn}, \mathrm{Cr}$, which show divergence in behaviour for some ashes. Thus, 4 hours can be taken as the optimum leaching time for water soluble metals.

Ion Exchangeable Fractions: Many metals leach more than $80 \%$ of their peak leaching concentrations after 4 hours, many of them even leaching more than $90 \%$ of their peak values. Mn shows low leaching at 4 hours for two ash samples, so it will not be correctly estimated at 4 hours. $\mathrm{Cu}, \mathrm{Fe}$, $\mathrm{Mg} \mathrm{Ni}$ and $\mathrm{Zn}$ exhibit moderate leaching for some ash samples. Thus, 4 hours can be asserted as the optimum leaching time for ion exchangeable conditions.

Acid Soluble Fractions: All major metals exhibit more than $90 \%$ of their maximum leaching concentrations at 24 hours, although $\mathrm{Ca}$ and $\mathrm{Na}$ exhibit about $85 \%$ of their maximum leaching concentrations for some ash samples at 24 hours. All minor elements show maximum leaching at 24 hours except $\mathrm{Mn}$ and $\mathrm{Cr}$ which show about $70 \%$ to $80 \%$ and $90 \%$ respectively of their maximum leaching concentrations at 24 hours. Thus, the optimum leaching time for acid soluble step can be fixed as 24 hours.

Reducible Solids Fractions: Na and Si show about 90\% of their maximum leaching concentrations at 24 hours for some ash samples, rest samples exhibit peak leaching or more than $95 \%$ of the peak leaching concentration at 24 hours. $\mathrm{Cr}, \mathrm{Cu}, \mathrm{Mg}, \mathrm{Ni}$ and $\mathrm{Pb}$ show about $90 \%$ of their maximum leaching concentrations at 24 hours for some ash samples. But most minor metals exhibit peak leaching concentrations at 24 hours for all ash samples. Thus, the optimum leaching for the reducible solids step can be fixed as 24 hours.

\section{ACKNOWLEDGEMENTS}

The authors are thankful to Centre for Environmental Science and Engineering, Indian Institute of Technology Bombay and scholars of Professor Dikshit Research Group for their help and cooperation to complete these experiments.

\section{REFERENCES}

[1] Sahu, S. K., Bhangare, R.C., Ajmal, P.Y., Sharma, S., Pandit, G.G., and Puranil, V.D., 2009 , Characterization and quantification of persistent organic pollutants in fly ash from coal fueled thermal power stations in India., Journal of Microchemical, 92, 92-96.

[2] Lokeshappa B., and Dikshit, A.K., 2011, Disposal and management of coal fly ash, Proc. ICLST, 11-14

[3] Adriano, D. C., Page, A. L., Elseewi, A. A., Chang A. C., and Straughan, I., 1980, Utilization and disposal of fly ash and other coal residues in terrestrial ecosystems: a, review., Journal of Environmental Quality, 9, 333-344.

[4] Aitken, R.L., and Bell, L.C., 1985, Plant uptake and phytotoxicity of boron in Australian fly ash., Journal of Plant and Soil, 84, 245-257.

[5] Mattigod, S. V., Rai, D., Eary, L. E., and Ainsworth, C. C., 1990, Geochemical factors controlling the mobilization of inorganic constituents from fossil fuel combustion residues: review of the major elements., Journal Environmental Quality, 19, 188-201.

[6] Yuan, C. C., Fang, W. C., Mui, D.T., and Chiang., H.L., 2009, Application of methods (sequential extraction procedures and high pressure digestion method) to fly ash particles to determine the elements: a case study of BCR 176., Journal of Hazardous Materials, 163, 578-587.

[7] Carlson, C.L., and Andriano, D. C., 1993, Environmental impacts of coal combustion residues, Journal of Environmental Quality., 22, 227-247.

[8] Turiel, F.J.L., Carvacho, W., Cabanas, M., Querol, X., and Soler, L.A., 1994, Mobility of heavy metals from coal fly ash., Environmental Geology, 23, 264-270.

[9] Worathanakul, P., Kongkachuichay, P., Noel, J.D., Suriyawong, A., Giammar, D.E. and Biswas, P., 2008, Evaluation of nanostructured sorbents in differential bed reactors for ele- 
mental mercury capture., Environmental Engineering Science, $25,1061-1070$.

[10] Groot, D. G.J., Wijkstra, J., Hoede, D., and vander Sloot, H., 1989, Leaching characteristics of selected elements from coal fly ash as a function of the acidity of the contact solution and the liquid/solid ratio. In Environmental aspects of stabilization and solidification of hazardous and radioactive wastes; Côté, P., Gilliam, T. M., Eds.; American Society for Testing and Materials: Philadelphia, PA, pp 170-183. 